\title{
Research behavior and effectiveness studies of college P.E. teachers
}

\author{
Kunlun Wei ${ }^{1}$ Haiyan Hao ${ }^{2}$ \\ ${ }^{1}$ Tianjin University of Technology and Education, Tianjin 300222, China \\ ${ }^{2}$ Weishan Road Middle School of Hexi District, Tianjin 300222,China
}

\begin{abstract}
As the current Students' Health Condition increasingly declining, the state administrative department of education urgently appeal to reform college P.E teaching, a lot of work has been done, but in college human resources evaluation system, the research work accounts for a large proportion, which seriously affect the real goals of education. This article attempts to study the behavior of $\mathrm{PE}$ teachers in scientific research, analyze the effectiveness of the research work acted on physical education as well as the adverse effects factors, and propose feasible suggestions.
\end{abstract}

Keywords: Sports research; Teachers literacy; Curriculum reform; Research behavior

\section{Preface}

According to the 2010 national physique monitoring, in recent years, the physical health of college students continues a downward trend. The reform on around the college physical education should be the most urgent problem to be sowed college Physical Education at present. But due to the influence of traditional concepts of education, a considerable amount of educational evaluation Workers hold a vague view of the purpose of teachers' evaluation scientific research level, or write more the more papers is sure to get greater achievements and value, as a result, they will get higher grades in the year-end appraisal or in the exam on the job classification. Meanwhile, scientific research results funds are weighted heavily in teacher evaluation. Teacher' reward, promotion treatment and status are closely related to it. So dominated by insatiable drive for benefit, some of the individual values of university teachers had been distorted, so some academic fraud become common. [1] In this context, this paper intended to promote the investigation and analysis of scientific understanding of PE teachers, as well as their behavior and achievements.

\section{Object and Methods of Study}

\subsection{Object of study}

Object of this paper is the PE teachers from some universities and colleges all over China, including PE class teachers, experts on sports.

\subsection{Research Methods}

\subsection{1 literature}

Through Chinese Text, Net and Articles databases, with "college teacher evaluation system, job evaluation, performance appraisal, sports research, academic fraud" searched as the keyword, or title, the relevant literature has been referred to by reading, analyzing, and sorting, a more comprehensive understanding of the Scientific Research 
of physical education teachers has come into being.

2.2.2 Survey

(1) interview

In this paper, based on research needs, an outline of interview is designed. On the feasibility of the questions and the rigor, the views of some experts were sought. As a result, instructive suggestions and methods can be gained.

(2)questionnaire

This questionnaire is based on some expert' advice. 300 copies ware handed out to P.E. Teachers in 12 colleges and universities in Tianjin, Liaoning, Gansu, Shandong, Guangdong and Sichuan provinces, and 268 were returned. The recovery rate is $81 \%$, valid questionnaires are 245 . The effective rate is $70 \%$.

2.2. 3 analysis of mathematical statistics Input the obtained data in spss 11.0 and do related statistical analysis and process to accurately analyze the understanding of scientific research and behavior of P.E. Teachers in universities and profoundly reveals the cause of the problem, thus effectively propose solutions.

\section{Results and analysis}

\subsection{Expectations and actuality of teacher evaluation}

Table 1 Importance of the understanding of teacher evaluation

\begin{tabular}{|l|l|l|l|l|l|l|l|l|}
\hline & $\begin{array}{l}\text { teaching } \\
\text { performa } \\
\text { nce } \\
\text { expectan } \\
\text { cy }\end{array}$ & $\begin{array}{l}\text { scientific } \\
\text { research } \\
\text { expectan } \\
\text { cy }\end{array}$ & $\begin{array}{l}\text { further } \\
\text { studies } \\
\text { and } \\
\text { training } \\
\text { expectan } \\
\text { cy }\end{array}$ & $\begin{array}{l}\text { number } \\
\text { of } \\
\text { papers } \\
\text { expectan } \\
\text { cy }\end{array}$ & $\begin{array}{l}\text { Actual } \\
\text { teaching } \\
\text { performa } \\
\text { nce }\end{array}$ & $\begin{array}{l}\text { Actual } \\
\text { scientific } \\
\text { research }\end{array}$ & $\begin{array}{l}\text { Actual } \\
\text { further } \\
\text { studies } \\
\text { and } \\
\text { training }\end{array}$ & $\begin{array}{l}\text { Actual } \\
\text { number } \\
\text { of } \\
\text { papers }\end{array}$ \\
\hline $\begin{array}{l}\text { Number } \\
\text { of people }\end{array}$ & 83 & 57 & 60 & 45 & 65 & 27 & 86 & 67 \\
\hline$\%$ & $33.9 \%$ & $23.3 \%$ & $24.5 \%$ & $18.4 \%$ & $26.5 \%$ & $11 \%$ & $35.1 \%$ & $27.3 \%$ \\
\hline
\end{tabular}

The main function of college sports is to build up students' body, to enhance physical and to provide people with body guarantees of their wisdom. The statistics in the table above show that comparing the top 4 most important options of teachers evaluation, the teaching performance of teachers is in the first row, which is consistent with the main function of public sports. The one comes in second place is the further studies or training, which indicates that teachers hope to enhance their own quality through further studies or training and behind lie the level of scientific research and the number of papers. But in fact the first rank should be the level of scientific research which is followed by the number of papers, teaching effectiveness, teachers' further education and training. So there is a big difference between the fact and the consensus of the majority of PE teachers. Perhaps the situation is closely linked with the index of the HR evaluation system in the universities in our country. Therefore, only the reform of the university teachers evaluation system, can help to fundamentally improve the quality of PE teaching and to improve the decline of college student's health and physique.

\subsection{After-school work of university P.E. teachers}

A teacher's spare-time activities(the behavior not done in class or something related) can reflect his or her working condition and work pressure. The survey involved a total of 245 teachers, among 
whom there are 65 assistants, 123 lecturers, 56 professors. As you can see from the image above, the ones whose title is assistant teacher majorly chose teaching design and further study of technology and theory the analysis shows that most of the teachers with this title are newly graduated students who are lack of work experience. At the same time, their job promotion pressure is relatively small; as lecturer nearly $75 \%$ of the teacher engaged in scientific research or write papers. Only $20 \%$ of them focused on their teaching; with the title of professor, the group of teachers also think scientific research should come first. And compared with lectures, professors spend more time on physical exercise. This shows that both the lecturers and professors are under high pressure. But professors may suffer more, and age is also a big problem. That makes them pay more attention on physical exercise. In conclusion, the vast majority of $\mathrm{PE}$ teachers in university suffer greater stress from promotion, which makes then fail to focus on their work to improve the quality of teaching.

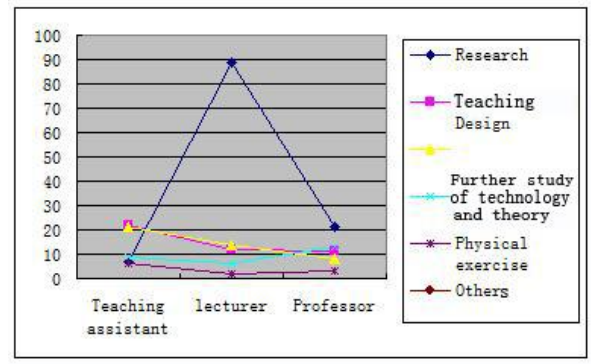

Figure 1. Map of the spare-time activities of P.E. Teachers

\subsection{Motivation of PE teachers engaging themselves in scientific research}

We can see from Figure 2 that 80 percent of teachers are engaged in scientific research in order to get promotion, which is consistent with the analysis of Figure 1. According to Figure
2, whether the lecturers or professors, the vast majority are engaged in scientific research. They are driven by the desire of job promotion rather than the need in improving the quality of teaching. It' $s$ no wonder that little improvement has been seen in the effectiveness of teaching quality with only 7 percent of the research results can be applied into teaching practice though much importance has been attached to both of the reform of physical education and the scientific research. It appears that the utilitarian value in their daily work occupies a very important role in their daily work. The majority of PE teachers are busy with teaching practice and the firsthand materials needed for research is hardly available, which is the root cause for the increasing academic fraud.

Dynamic analysis diagram research

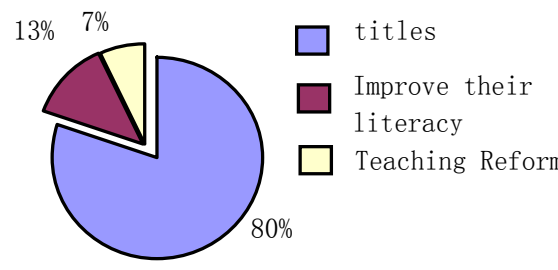

Dynamic analysis diagram research

Figure 2: Research and analysis of motives

\subsection{The Transformation of the Value of Scientific Research}

Assuming that each university has 25 professional teachers, with an average annual publication of a paper and each article has an innovative point, so every year there are 25 researches needing time to prove its worth, which means theoretically each school will have 25 new changes or new atmosphere. In the survey, 87 percent of teachers assume that the research results obtained in research can be applied to teaching 
practice. However, for 81.5 percent of schools, the PE classes remain the same way as they used to be with the same sports and items. In some school the sports items are the same for the two semesters during a year and there' $\mathrm{s}$ no sign of changing and reform. A related survey was conducted to investigate the application efficiency of research results into Physical Education classes. According to the survey, only 9.8 percent of PE teachers assume that the effect is obvious. 15.3 percent think that the effect is not obvious or doesn' $t$ exist. The rest 44.9 percent simply do not apply the scientific research at all. The analysis shows that a lot of research results have not been verified in practice.

\subsection{The effective ways for $P E$ teachers to improve their literacy and to promote curriculum reform}

Options have been designed in terms of the elements that account for the students, attendance as well as the intended ways for PE teachers to improve their literacy.

From the data in figure 3 can the following conclusions be drown:61percent of the students ' attendance for the sports learning and training is attributed to the compulsive competition tasks or examinations which indicates it' $s$ the pressure instead of the positivity that impulse more than half of the students. 45 percent of attendance is attributed to the attraction of the newly emerging sport which shows the power of students' curiosity. Only 38 percent of the students take it as a hobby which on the contrary indicates that many students don' t develop a habit of exercising, thus having no correct health values. The charm of PE teachers contributes to only 23 percent which shows the teachers themselves lack for the appeal to the students.
Most of the teachers, if not all, has realized that they need to keep learning to enhance their operational capacity and technical level. Among their selfmethodological approaches, business training and education takes up 67 percent, which is consistent with the result of another survey entitled" how often do you attend a training", in which 78 percent of the teachers spend two years or longer to participate in a training. 40 percent of teachers hope to obtain knowledge and skills by exchanging with other universities. Only 13 percent of teachers believe that through scientific research can they upgrade their level, which is far less than 100 percent, which is the theoretically percentage of the teachers who reckon that scientific research help improve themselves[3].

\section{Conclusions and recommendations}

\subsection{Conclusion}

The quantity and quality of teacher' $s$ scientific research account for too much in teacher' $s$ evaluation system and job promotion. Driven by the utilitarian heart, teachers has little intention to transform their research into practice, thus the losing the value of research. Too much pressure leads the teachers to spend too much energy and time on their research instead of studying how to improve the efficiency of physical classroom teaching. The teachers way of improving themselves is too simplified and most are self-taught, which is not conductive to grasp the trend of the times and updated knowledge.

\section{2. recommendations}

4.2.1 Reform of College Sports Teachers' Evaluation System and Reduce the Proportion of scientific research in it

The unified evaluation index is converted into differentiating assessment. 
Teachers are divided into pedagogical teachers and scientific ones in order to make assessment separately according to their special functions and objectives thus reducing the research pressure on ordinary teachers. Reduce the proportion of the research papers in evaluation. The utilitarian research is converted to action research which is mainly aimed at improving the quality of teaching and actual work. Work with the experts to solve the practical pedagogical problems. As for the scientific research achievements incapacitation, the research period is extended in order to focus on the practical effectiveness of the results.

4.2.2 Enhance the overall quality of majority of teachers via vocational training

With strong curiosity and ambition, college students are curious and expectant for new things. There for it' $s$ necessary to impart the teachers with the newly findings of experts in the form of training so that they can grasp the trend of the times and bring some emerging sports skills into daily classes in order to attract and motivate students to learn and raise their positivity. In this way can the reform of college physical education be conducted progressively and effectively.

4.2.3 Physical education is extended to the extracurricular counseling on the basis of class

For a long time, the majority of teachers' education function is mainly reflected in the classroom. Except some of the schools' sports talented students or high level players, the physical education teachers, counseling for ordinary students is almost zero. Extracurricular physical activity counseling is actually more important than classroom exercises sports activities. In addition to studying the reform of classroom teaching, the majority of the teachers are supposed to focus on the action research and reform the management of college extracurricular sports which will promote the formation of the physical exercise habit and stimulate their positivity and enthusiasm thus enhancing physical fitness.

4.2.4 Give full play to teachers with high academic titles

High-grade teachers (professors) have no pressure on job promotion and has a high level of scientific research as well as a wealth of teaching experience. They play an extremely significant role in daily work. Guided by them, the young teachers can grow up more faster.

\section{Acknowledgment}

This study was part of the research project of Tianjin University of Technology and education's Research Foundation (SK10 - 08).

\section{References}

[1] Liu Yun, university teacher evaluation system construction [D], Chongqing University, master's thesis,

2008: 25-27.

[2] Zhong Yu, China's University Teachers Evaluation System [D], Southwest Jiaotong University ,2006:42 -47

[3] Wang Hong Kong, China's sports schools Factors Affecting

Teachers' Continuing Education System

Construction [D],

Beijing Sport University dissertation ,2008:10 -12

[4] Liu Zhihong, school sports teaching evaluation system construction and operability study, [D] Hebei Normal dissertation, 2007:190-193 